\title{
The Distal Row Carpal Bones - A Morphometric Treatise
}

\section{IJCRR}

Section: Healthcare

Sci. Journal Impact

Factor: 6.1 (2018)

ICV: 90.90 (2018)

(c) (i) (8)

Copyright@IJCRR

\section{Ripujit Randhawa', Ravikant Sharma', JS Kullar'2, Gaurav Agnihotri ${ }^{3}$}

'Senior Resident, Department of Anatomy, Government Medical College, Amritsar, India; ${ }^{2}$ Professor, Department of Anatomy, Government Medical College, Amritsar, India; ${ }^{3}$ Professor, Department of Anatomy, Government Medical College, Amritsar, lndia; ${ }^{4}$ Associate Professor, Department of Anatomy, Government Medical College, Amritsar, India.

\section{ABSTRACT}

Introduction: A comprehension of customized geometry of carpals is essential for preoperative planning and creation of implants and fixators. The present morphometric treatise on distal carpal bones has an anatomical, anthropological and clinical significance.

Objective: To assess the gross morphological features with special emphasis on the dimensions and configurations of the articular facets.

Methods: The study was done on 480 distal carpal bones.120 bones (60 right and 60 left) of each type (hamate, capitate, trapezoid and trapezium) were selected from the bone museum at Government Medical College, Amritsar. The morphometry and morphology of each distal carpal bone were studied.

Results: The mean values as measured for right and left-sided bones when compared were found to be statistically insignificant ('p' value $>0.01$ ) for most parameters. A statistical significance was observed for the width of capitate at its base ('p' value $<0.001$ ), length of the distal surface of a trapezoid for articulation with the base of 2nd metacarpal ( $p$-value $<0.01)$ and width of groove on the palmar surface of the trapezium ( $p$-value $<0.01$ ). No vascular foramina were observable on the bend of the hook of hamate in the present study. This pioneering study on distal row carpals provides important data on the incidence of merging and discontinuity of articular facets.

Conclusions: The study provides pioneer results and addresses the paucity of a baseline 'morphometric criterion' for distal carpals. The normative data is invaluable for comprehension of wrist pathologic conditions like Kienbock's disease, post-traumatic arthritis and outcome of surgical procedures such as a proximal row corpectomy.

Key Words: Distal carpals, Morphometry, Morphology

\section{INTRODUCTION}

A comprehension of the customized geometry of distal carpals is essential for preoperative planning and creation of implants and fixators. ${ }^{1}$ The distal carpals are prone to fractures and avascular necrosis. The distal morphology and morphometry influence the development or progression of various wrist pathologic conditions, such as kienbock's disease and post-traumatic arthritis and the outcome of certain surgical procedures. The fracture of the hook of hamate is quite common in athletes, especially baseball players, golfers and tennis players. ${ }^{1,2}$ Trapezoid fractures occur in $0.4 \%$ of all carpal injuries. ${ }^{3}$ The bend of the hamate hook could be its weakest part and is prone to avascular necrosis. ${ }^{4}$ The capitate is another bone prone to avascular necrosis. ${ }^{5}$ The size of the trapezium must be taken into consideration when implanting a trapeziometacarpal prosthesis. ${ }^{6}$

The distal level of carpal tunnel tends to have an elevated pressure $^{7}$, and it is structurally stiffer than proximal level. ${ }^{8}$ The distal row is considered to be tightly bound with little intercarpal motion during wrist movement ${ }^{9-11}$ especially at the trapezium-trapezoid and trapezoid-capitate joints. ${ }^{10,11}$ The carpal arch width is the distance between the hook of hamate and the ridge of the trapezium. Narrowing and widening of carpal arch width can occur during wrist motion ${ }^{12}$, after carpal tunnel release ${ }^{12-15}$, or during cadaveric experimentation. ${ }^{16-18}$

\section{Corresponding Author:}

Dr. Gaurav Agnihotri, Associate Professor, Department of Anatomy, Government Medical College, Amritsar, India. Email: anatomygaurav@yahoo.com.

ISSN: 2231-2196 (Print)

Received: 21.07 .2020
ISSN: 0975-5241 (Online)

Revised: 12.09 .2020
Accepted: 28.10 .2020
Published: 14.12 .2020 
Anthropometric studies of the hand bones also have forensic significance in postmortem identification of the human remains. ${ }^{19,20}$ The present morphometric treatise of distal carpal bones has an anatomical, anthropological and clinical significance.

\section{MATERIALS AND METHODS}

The study was done on 480 distal carpal bones. 120 bones( 60 right and 60 left) of each type (hamate, capitate, trapezoid and trapezium) were selected from the bone museum at Government Medical College, Amritsar. The morphometry and morphology of each distal carpal bone were studied (Figures 1-6).

Written permission was taken from the Institutional Ethical Committee, Government Medical College, Amritsar, Punjab, India to conduct the study. It was ensured that all distal carpals included in the study were dry, macerated and complete in all respects.

\section{General morphometric measurements}

The length and width of each distal carpal bone and its articular facets was measured. The bones were placed in anatomical position and outline was marked on graph paper. The measurements were done using vernier callipers. The length and width of facets were measured directly using vernier callipers.

The number of vascular foramina was noted using a magnifying lens.

\section{Morphometric features specific to particular bones}

Height of hook of hamate: It was measured by directly using digital vernier from base to tip.

Circumference of the hamate hook: It was measured by winding around a thread around the hook of hamate bone at the base. A point was marked on the thread using a permanent marker, this thread was then placed stretched on a plain paper and the dimension measured with a vernier calliper.

Length of distal palmar angle on the lateral surface: The distal palmar angle on the lateral surface was identified and its length was measured using vernier callipers.

Width of capitate in middle: Each bone was placed on graph paper in anatomical position and its outline was traced onto the graph paper. The most prominent points on the medial side and lateral side of the narrow constricted part of capitate were marked. The width was then measured using the digital vernier calliper.

Width of capitate at base: Each bone was placed on graph paper in anatomical position and its outline was traced onto the graph paper. The most prominent point on the medial side and the most prominent point on the lateral side of the most proximal part of the bone were marked. Then the width at the base was measured using the digital vernier calliper.

Circumference of capitate head: It was measured by winding a thread around the head of the capitate bone. A point was marked on the thread using the permanent marker, this thread was then placed on plain paper and circumference was measured using a digital vernier calliper.

Tubercle circumference of trapezium: It was measured by winding around a thread around the tubercle of trapezium bone. A point was marked on the thread using the permanent marker, this thread was then placed on plain paper and circumference was measured using a digital vernier calliper.

Width of groove on the palmar surface of trapezium: On the palmar surface lies a deep groove on the medial side of tubercle. The width of this groove was measured by directly placing the vernier calliper over the bone.

\section{Statistical analysis}

The measures for the right and left sides were compared utilizing the unpaired ' $t$ 'test. This is the independent t-test. The predictive ' $p$ ' value was determined. A ' $p$ ' value of $<0.05$ was considered to be statistically significant.

\section{RESULTS}

From table 1 (depicting dimensions of hamate bone), It is clear that no statistically significant differences in the average values of right and left hamates $(p>0.01)$ was observed. The same was true for all but one parameter measured for right and left capitate Table 2), Trapezoid and trapezium bones. The width of the capitate at its base, the length of the distal surface of a trapezoid for articulation with the base of second metacarpal and width of groove on the palmar surface of trapezium as measured for right and left sides when compared came to be significant $(\mathrm{p}<0.01)$.

The vascular foramina were found on all hamate hooks predominantly on the radial base and ulnar tip of the hook of the hamate. The incidence of these vascular foramina at the radial base and ulnar tip came out to be $90 \%$ and $66 \%$ respectively.No, vascular foramen was observed at the end of the hook of the hamate.

\section{DISCUSSION}

The present study on 480 human carpal bones of the distal row assessed the gross morphological features with special emphasis on the dimensions and configurations of the articular facets. The results so obtained were compared with the 
results of a very limited number of earlier studies available to provide a database of the normal values for future comparative studies. The height of the hamate hook was measured previously by Kumar 'et al'4 (right side-9.5 +1.35 and left side $10.14 \pm 1.03$ ) and our values agree with them. The articular facet for capitate was observed to be oblong and continuous in shape in the majority of bones but exhibited discontinuity in36 specimens (24 right sides and 12 left sides).

All hamate hooks had vascular foramen on them. These foramina were found predominantly on the radial base and ulnar tip of the hook of the hamate. The incidence of these vascular foramina at the radial base and ulnar tip came out to be $90 \%$ and $66 \%$ respectively. No vascular foramina were observed at the end of the hook, in accordance to study of by Kumar 'et al' ${ }^{4}$ Hence, we can conclude that the bend of the hook is an area prone to avascular necrosis. It was observed that the lateral surface presents a grooved region known as neck which provided attachment to the ligaments. ${ }^{21}$ In our study, this neck was seen extending up to the palmar surface in eight specimens (incidence 6.6\%). Similarly, the articular facet for hamate on a medial surface in capitate (oblong shape in the majority) exhibited a detached smooth facet in its distal part in thirty-six specimens. No data was available for comparison of study, so the present study is a pioneer study which provides references for further similar types of studies. ${ }^{19,20}$

In trapezoid bone, the smooth articular surface for capitate on the medial surface was observed to present a groove at its lower end in thirty-six specimens(incidence $30 \%$ ). The trapezium dimensions determined in the present study were on lower side vis-a-vis the study by Loisel $\mathrm{F}$ et $\mathrm{al}^{6}$ and this could be attributable to the impact of ethnicity on bone morphometry. ${ }^{22}$ The two portions of the medial surface of the trapezium are proximal(larger and for trapezoid) and distal(for the base of the second metacarpal) facets. These were seen to have merged within the absence of the distinct ridge separating them in sixteen specimens (incidence $13.33 \%)$.

\section{CONCLUSION}

In human anatomy, the main role of the wrist is to facilitate the effective positioning of the hand. The proximal row bones are more mobile at interosseous joints compared to the more distal row bones. The hallmark of the distal row bones is their geometric complexity. The quantified characterization of distal carpals has been overlooked in research. The present study is a pioneer morphometric treatise on distal carpals and the results and observations have anatomical, anthropological, forensic and clinical implications.

\section{ACKNOWLEDGEMENTS}

The authors acknowledge the efforts of the support staff in the department of anatomy including the beekeeper of the department and the photo cine officer for their valuable inputs.

\section{Source of funding: NA}

Conflict of interest: Nil

\section{REFERENCES}

1. Arsic S, Vitkovic N, Manic M, Stojanovic M. Morphological Properties of the Hand Bones Important for their 3D Geometrical Modelling. ICT Forum 2014;130.

2. Demirkan F, Calandruccio JH, DiAngelo D. Biomechanical evaluation of flexor tendon function after hamate hook excision. J Hand Surg. 2003; 28:138-43.

3. Rita M. Sadowski, Richard D. Montilla. Rare Isolated Trapezoid Fracture: A case Report. 2008; 3: 372-4.

4. Kumar B, Pandey A, Kotian S. Morphometry and Morphology of Hamate Hook and its Clinical Implications. Marmara Med J. 2011;24:192-5.

5. Prabhu L, Murlimanju B, Jiji P, Pai M. Vascular Foramina of the Capitate Bone of the Hand - an Anatomical Study World Academy of Science, Engineering and Technology International Journal of Medical and Health Sciences 2015;2:8.

6. Loisel F, Chapuy S, Rey PB, Obert L, Parratte B, Tatu L, Lepage D. Dimensions of the trapezium bone: a cadaver and CT study. Surg Radiol Anat. 2015; 37(7): 787-92.

7. Goss BC, Agee J M. Dynamics of Intracarpal Tunnel Pressure in Patients with carpal tunnel syndrome. J. Hand Surg. Am. 2010;35(2):197-206.

8. Xiu KH, Kim JH, and Li ZM. Biomechanics of the transverse carpal arch under carpal Bone loading Clin. Biomech. 2010; 25(8): 776-80

9. De Lange A, Kauer JM, and Huiskes R. Kinematic Behavior of the Human Wrist Joint: A Roentgen-Stereophotogrammetric Analysis. J. Orthop. Res. 1985; 3(1):56-64.

10. Ruby LK, Cooney WP et al. Relative Motion of Selected Carpal Bones: A kinematic analysis of the normal wrist. J. Hand Surg. 1988;13(1):1-10.

11. Moritomo H, Viegas SF, Elder K, Nakamura K, Dasilva MF, and Patterson RM. The Scaphotrapezio-Trapezoidal Joint. Part 2: A Kinematic Study. J. Hand Surg. 2000;25(5):911-20.

12. Garcia-Elias M, Sanchez-Freijo JM, Salo JM, and LluchA L. Dynamic changes of the transverse carpal arch during flexionextension of the wrist: Effects of Sectioning the Transverse Carpal Ligament. J. Hand Surg. 1992;17(6):1017-9.

13. Kuhlmann N, Tubiana R, and Lisfranc R. Contribution of Anatomy to the understanding of carpal tunnel compression syndromes and sequelae of decompression operations. Rev. Chir. Orthop. Reparatrice Appar. Mot. 1978;64(1): 59-70.

14. Flores LP, Cavalcante TF, Neto OR, and Alcantara FS. Quantitative analysis of the variation in angles of the carpal arch after open and endoscopic carpal tunnel release. Clinical Article. J. Neurosurg. 2009;111(2): 311-6.

15. Gartsman GM, Kovach JC, Crouch CC, Noble PC, and Bennett JB. Carpal arch alteration after carpal tunnel release. J. Hand Surg. 1986;11(3):372-4.

16. Li ZM, Tang J, Chakan M, Kaz R. Carpal tunnel expansion by palmary directed forces to the transverse carpal ligament. J Bio- 
mech Eng. 2009;131(8):081011.

17. Sucher BM, and Hinrichs RN. Manipulative treatment of carpal tunnel syndrome: Biomechanical and osteopathic intervention to increase the length of the transverse carpal ligament. J. Am. Osteopath Assoc. 1998;98(12):679-86.

18. Li Z M, Masters TL, and Mondello TA. Area and shape changes of the carpal tunnel in response to tunnel pressure. J. Orthop. Res. 2011;29(12):1951-6.

19. Kanchan T, Krishan K. Anthropometry of hand in sex determination of dismembered remains - a review of the literature. Journal of Forensic and Legal Medicine. 2011;18(1):14-7.
20. Ghada A. Gender determination from hand bones length and volume using multidetector computed tomography: A study in Egyptian people. Journal of Forensic Medicine. 2011;18(6):24652

21. Gupta A, Risitano G, Crawford R, Burke F. Fracture of the hook of the hamate. Injury 1989;20:284-6.

22. Farago D and Kiss R M. Geometric and mechanical characterization of human carpal bones - A preliminary study. Periodica Polytechnica Civil Engineering.2020;64(1):138-43.

Table 1: Dimensions for hamate bone

\begin{tabular}{|c|c|c|c|c|c|c|c|}
\hline \multirow[t]{2}{*}{ Parameters } & \multicolumn{2}{|c|}{ Right $(n=60)$} & \multicolumn{2}{|c|}{ Left $(n=60)$} & \multicolumn{2}{|c|}{ Total } & \multirow{2}{*}{$\begin{array}{l}\text { 'p' } \\
\text { value }\end{array}$} \\
\hline & $\begin{array}{l}\text { Mean } \\
(\mathbf{m m})\end{array}$ & SD & $\begin{array}{l}\text { Mean } \\
(\mathrm{mm})\end{array}$ & SD & $\begin{array}{l}\text { Mean } \\
(\mathrm{mm})\end{array}$ & SD & \\
\hline Length & 18.12 & 2.51 & 18.00 & 2.76 & 18.06 & 0.18 & 0.90 \\
\hline Width & 14.22 & 1.65 & 14.17 & 2.24 & 14.20 & 0.42 & 0.94 \\
\hline $\begin{array}{l}\text { Height of } \\
\text { Hamate hook }\end{array}$ & 10.28 & 0.27 & 10.56 & 0.54 & 10.42 & 0.19 & 0.09 \\
\hline $\begin{array}{l}\text { Circumference hamate hook } \\
\text { (at the base) }\end{array}$ & 24.73 & 1.89 & 26.24 & 2.26 & $25 \cdot 49$ & 0.26 & 0.06 \\
\hline $\begin{array}{l}\text { Length of distal palmar angle on } \\
\text { lateral surface }\end{array}$ & $5 \cdot 31$ & 0.31 & $5 \cdot 33$ & 0.32 & $5 \cdot 32$ & 0.01 & 0.86 \\
\hline $\begin{array}{l}\text { Width of facet on proximal } \\
\text { surface }\end{array}$ & 4.43 & 0.29 & $4 \cdot 52$ & 0.38 & $4 \cdot 48$ & 0.06 & 0.48 \\
\hline $\begin{array}{l}\text { Length of facet on proximal } \\
\text { surface }\end{array}$ & 5.08 & 0.44 & 5.22 & 0.57 & 5.15 & 0.09 & 0.46 \\
\hline
\end{tabular}

Table 2: Dimensions for capitate bone

\begin{tabular}{|c|c|c|c|c|c|c|c|}
\hline \multirow[t]{2}{*}{ Parameters } & \multicolumn{2}{|c|}{ Right $(\mathbf{n}=60)$} & \multicolumn{2}{|c|}{ Left $(n=60)$} & \multicolumn{2}{|c|}{ Total } & \multirow[t]{2}{*}{ 'p' value } \\
\hline & $\begin{array}{l}\text { Mean } \\
(\mathbf{m m})\end{array}$ & S.D. & $\begin{array}{l}\text { Mean } \\
(\mathbf{m m})\end{array}$ & S.D. & $\begin{array}{l}\text { Mean } \\
(\mathbf{m m})\end{array}$ & S.D. & \\
\hline Length & $24 \cdot 55$ & 2.26 & 24.03 & 2.08 & 24.29 & 0.13 & 0.52 \\
\hline Width in the middle & 13.25 & 2.44 & $13 \cdot 34$ & 1.80 & $13 \cdot 30$ & 2.12 & 0.91 \\
\hline Width at base & 7.63 & 1.63 & 13.34 & 1.80 & 10.49 & 0.12 & 0.001 \\
\hline $\begin{array}{l}\text { Circumference } \\
\text { of head }\end{array}$ & 39.46 & 9.13 & 41.54 & 1.13 & 40.50 & 5.66 & 0.42 \\
\hline $\begin{array}{l}\text { Width of facet on medial } \\
\text { surface }\end{array}$ & 6.34 & 0.37 & 6.53 & 0.40 & 6.44 & 0.02 & 0.18 \\
\hline $\begin{array}{l}\text { Length of facet on medial } \\
\text { surface }\end{array}$ & 17.12 & 1.32 & 17.00 & 1.06 & 17.06 & 0.18 & 0.79 \\
\hline $\begin{array}{l}\text { Length of facet on dorso- } \\
\text { medial surface }\end{array}$ & 4.13 & 0.38 & 3.96 & 0.33 & 4.05 & 0.04 & 0.20 \\
\hline $\begin{array}{l}\text { Width of facet on dorso- } \\
\text { medial surface }\end{array}$ & 4.29 & 0.48 & 4.13 & 0.30 & 4.21 & 0.13 & 0.30 \\
\hline
\end{tabular}


Table 3: Dimensions for trapezoid bone

\begin{tabular}{|c|c|c|c|c|c|c|c|}
\hline \multirow[t]{2}{*}{ Parameters } & \multicolumn{2}{|c|}{ Right (n=6o) } & \multicolumn{2}{|c|}{ Left $(n=60)$} & \multicolumn{2}{|c|}{ Total } & \multirow[t]{2}{*}{ 'p'value } \\
\hline & $\begin{array}{l}\text { Mean } \\
(\mathbf{m m})\end{array}$ & SD & $\begin{array}{l}\text { Mean } \\
(\mathrm{mm})\end{array}$ & SD & $\begin{array}{l}\text { Mean } \\
(\mathrm{mm})\end{array}$ & SD & \\
\hline Length & 12.82 & 2.24 & 11.66 & 1.89 & 12.24 & 0.25 & 0.13 \\
\hline Width & 11.60 & 2.13 & 11.24 & 2.08 & 11.42 & 0.04 & 0.64 \\
\hline $\begin{array}{l}\text { Length of concave facet on medial } \\
\text { surface }\end{array}$ & 8.68 & 1.83 & 8.34 & 1.01 & 8.51 & 0.58 & 0.53 \\
\hline $\begin{array}{l}\text { Width of concave facet on medial } \\
\text { surface }\end{array}$ & $5 \cdot 76$ & 0.91 & 5.65 & 0.77 & $5 \cdot 71$ & 0.10 & 0.72 \\
\hline $\begin{array}{l}\text { Length of distal surface for } \\
\text { articulation with base of second } \\
\text { metacarpal }\end{array}$ & 13.16 & 1.26 & 12.26 & 1.56 & 12.71 & 0.21 & 0.09 \\
\hline $\begin{array}{l}\text { Width of distal surface for } \\
\text { articulation with base of second } \\
\text { metacarpal }\end{array}$ & 5.88 & 0.91 & $5 \cdot 5^{8}$ & 0.93 & 5.73 & 0.01 & 0.37 \\
\hline
\end{tabular}

Table 4: Dimensions for trapezium

\begin{tabular}{|c|c|c|c|c|c|c|c|}
\hline \multirow[t]{2}{*}{ Parameters } & \multicolumn{2}{|c|}{ Right (n=6o) } & \multicolumn{2}{|c|}{ Left $(n=60)$} & \multicolumn{2}{|c|}{ Total } & \multirow[t]{2}{*}{ 'p'value } \\
\hline & $\begin{array}{l}\text { Mean } \\
(\mathrm{mm})\end{array}$ & SD & $\begin{array}{l}\text { Mean } \\
(\mathrm{mm})\end{array}$ & SD & $\begin{array}{l}\text { Mean } \\
(\mathrm{mm})\end{array}$ & SD & \\
\hline Length & $15 \cdot 35$ & 2.38 & 16.02 & 1.84 & 15.69 & 0.38 & 0.39 \\
\hline Width & 14.86 & 2.44 & 14.00 & 3.18 & 14.43 & 0.52 & 0.41 \\
\hline Tubercle circumference & 25.96 & 1.36 & 27.00 & 2.02 & 26.48 & 0.47 & 0.10 \\
\hline $\begin{array}{l}\text { Width of groove on palmar } \\
\text { surface }\end{array}$ & 3.62 & 0.69 & 3.15 & 0.62 & $3 \cdot 39$ & 0.05 & 0.05 \\
\hline $\begin{array}{l}\text { Width of ridge on proximal } \\
\text { surface for articulation with } \\
\text { scaphoid }\end{array}$ & $4 \cdot 34$ & 0.24 & $4 \cdot 40$ & 0.40 & $4 \cdot 37$ & 0.11 & 0.62 \\
\hline
\end{tabular}

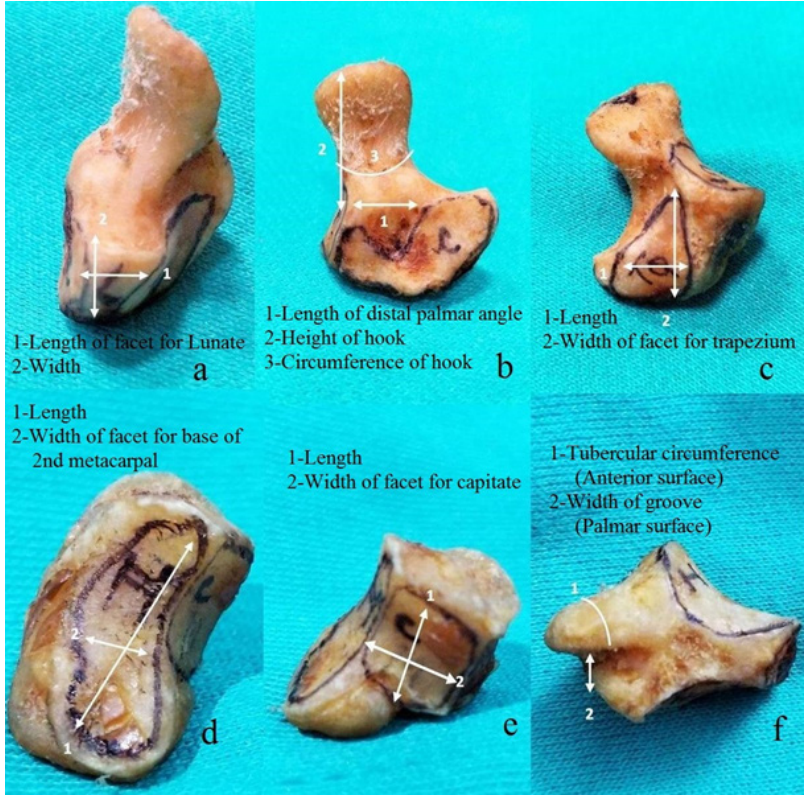

Figure 1: Showing some measurements on distal carpals (aProximal surface of hamate; b- Lateral surface of hamate; c- medial surface of hamate; $d$ - distal surface of trapezoid; e- medial surface of trapezoid; f- anterior and palmar surface of trapezium).

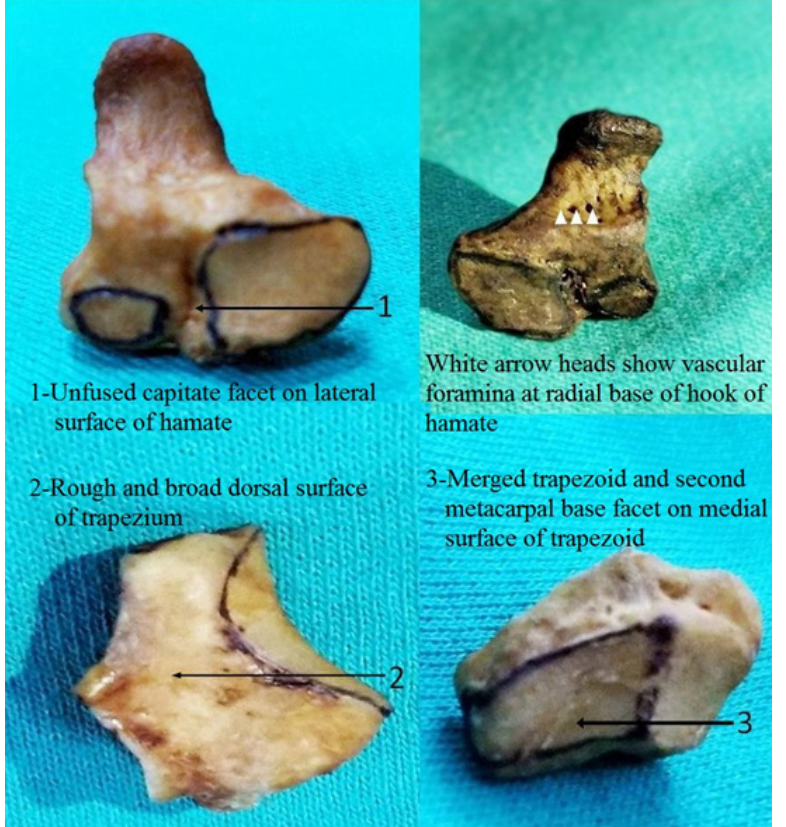

Figure 2: Showing some morphological characteristics of distal carpals. 


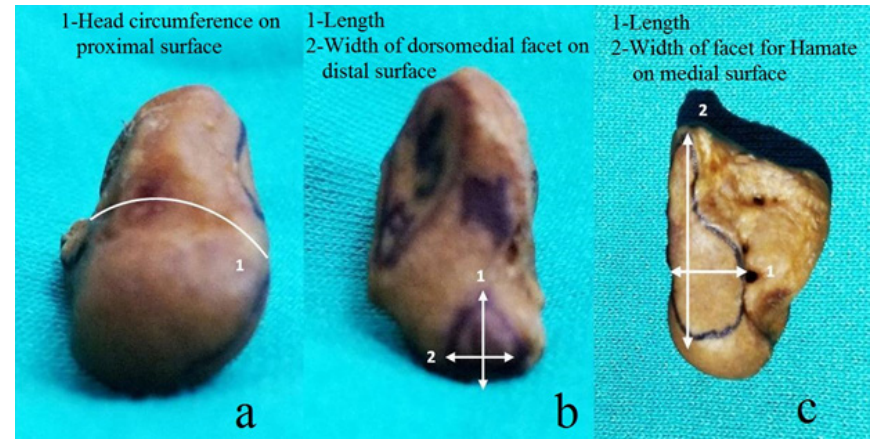

Figure 3: Showing Mmeasurements on capitate bone.

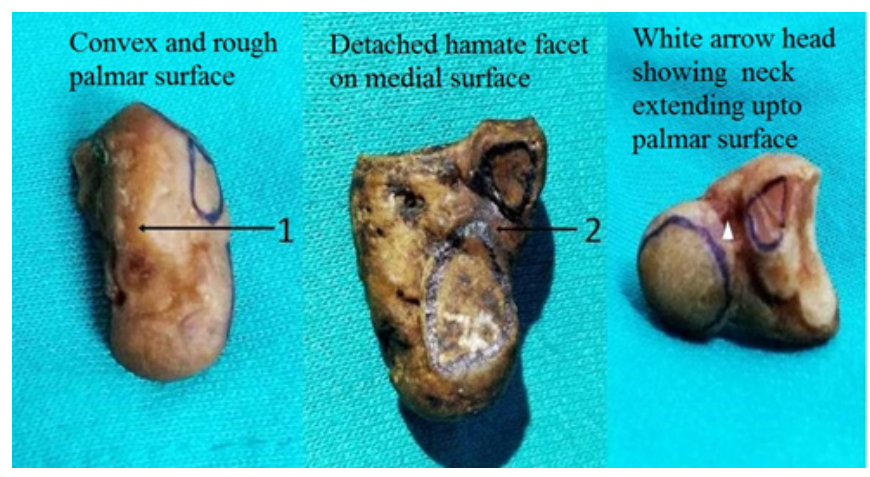

Figure 4: Showing morphological characteristics of capitate bone.
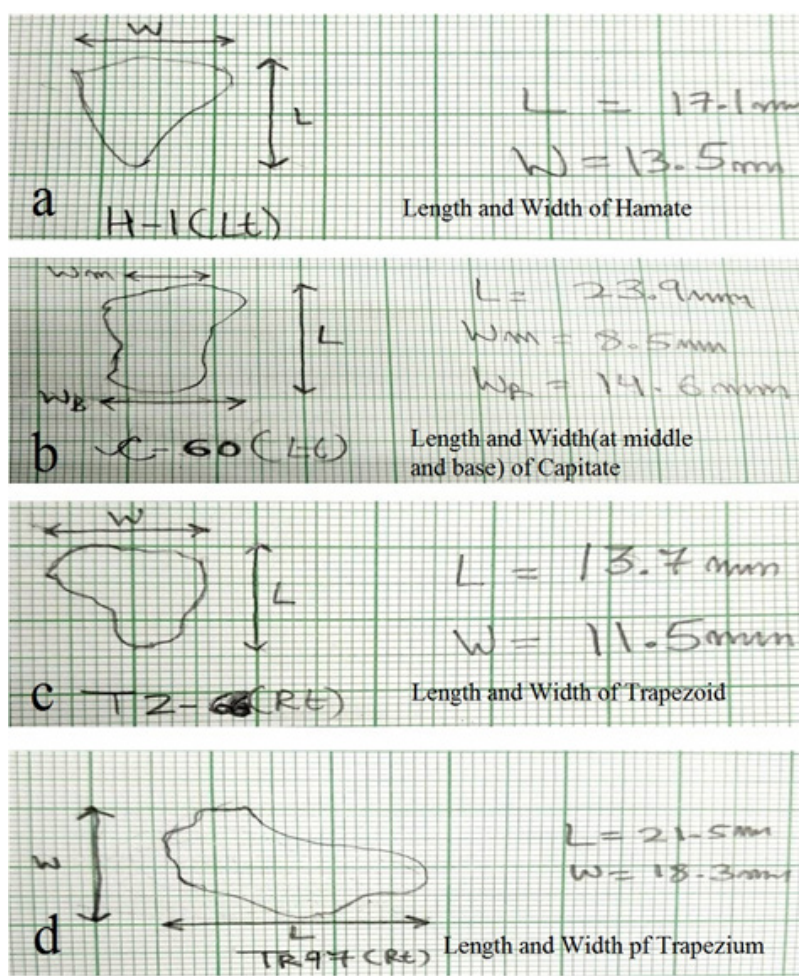

Figure 5: Showing measurements of dimensions of distal carpals on graph paper.

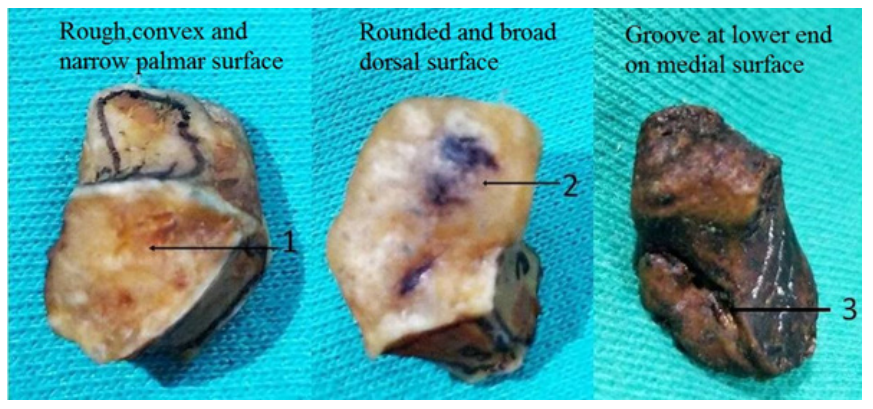

Figure 6: Showing morphological characteristics of trapezoid bone. 